\title{
Expression of mRNA for vascular endothelial growth factor in human placenta
}

\author{
A. M. Sharkey ${ }^{1}$, D. S. Charnock-Jones ${ }^{1}$, C. A. Boocock ${ }^{1}$, \\ K. D. Brown ${ }^{2}$ and S. K. Smith ${ }^{1}$ \\ ${ }^{1}$ Department of Obstetrics and Gynaecology, University of Cambridge, Rosie Maternity Hospital, \\ Robinson Way, Cambridge CB2 2SW, UK, and ${ }^{2}$ Department of Biochemistry, Institute of Animal \\ Physiology and Genetics Research, Cambridge CB2 4AT, UK
}

Implantation and growth of the placenta requires extensive angiogenesis to establish the vascular structures involved in exchange. Failure to establish adequate blood supply to the fetus may have serious clinical consequences such as intrauterine growth retardation. Vascular endothelial cell growth factor (VEGF) is a recently identified growth factor with significant angiogenic properties. We have demonstrated the presence of four species of mRNA encoding VEGF in both first trimester and term placenta. In situ hybridization was used to localize the sites of expression of VEGF mRNA in these tissues. VEGF expression was seen in villous trophoblast in the first trimester and in extravillous trophoblast at term, and in both fetal macrophages within the villi and maternal macrophages in the decidua. Glandular epithelium in maternal decidua also expressed VEGF mRNA. The strongest site of expression was in maternal macrophages adjacent to Nitabuch's stria, a zone of necrosis at the site of implantation. This complex pattern of expression suggests that VEGF is involved in angiogenesis on both maternal and fetal sides of the placenta and that macrophages are the primary source of VEGF. However, VEGF may also play a role in term placenta, when extensive angiogenesis has diminished, possibly regulating vascular permeability.

\section{Introduction}

The development of the human placenta begins with implantation and invasion of the endometrium by migrating trophoblast cells. While the trophoblast is penetrating, the maternal arteries continue to elongate until well into the first trimester. Extensive angiogenesis occurs both in the fetal villi and in the maternal decidua, to establish the vascular structures required for exchange (Findlay, 1986). This involves proliferation, migration and maturation of maternal and fetal endothelial cells (reviewed in Klagsbrun and D'Amore, 1991).

Many angiogenic growth factors are now recognized including acidic and basic fibroblast growth factor (FGF) and vascular endothelial growth factor (VEGF) (Folkman and Klagsbrun, 1987; Gospodarowicz et al., 1987; Ferrara and Henzel, 1989). We have recently demonstrated mRNA encoding all three of these angiogenic growth factors in human endometrium. (Charnock-Jones et al., 1993; Ferriani et al., 1993). VEGF is a specific mitogen for endothelial cells and is involved in angiogenesis (Ferrara ef al., 1992). Purified VEGF is a dimer of approximately $46 \mathrm{kDa}$ (Ferrara and Henzel, 1989; Gospodarowicz et al., 1989). Analysis of cDNA clones predicts five isoforms of 206 , $189,165,145$ and 121 amino acids, arising by alternative splicing of exons 6-8 (Houck et al., 1992; Charnock-Jones et al., 1993). All of these peptides contain an amino-terminal signal

Received 9 February 1993. sequence required for secretion. Recently, the fms-like tyrosine kinase (flt), a member of the transmembrane receptor tyrosine kinase family, has been shown to be a specific receptor for VEGF. Flt was cloned from a human placental cDNA library (De Vries et al., 1992). Iodinated VEGF binds only to vascular endothelial cells in tissues, indicating that these are its cellular target (Jakeman et al., 1992).

We previously showed that mRNAs encoding the four smallest isoforms of VEGF are present in human endometrium (Charnock-Jones et al., 1993). mRNA encoding VEGF $_{145}$ appeared to be specifically expressed in uterine tissue, although it is not yet known whether this variant has biological activity. In situ hybridization in endometrium of nonpregnant women showed that VEGF is expressed by both stromal and glandular cells during the proliferative phase of the cycle, with greatly increased expression in the glands of the secretory endometrium. However, the greatest intensity of hybridization was found in endometrial glands during menstruation, suggesting that VEGF is involved in angiogenesis following menstruation in the normal cycle. In view of this, and the report of the presence of a VEGF clone in a human placental cDNA library (Houck et al., 1991), we used the techniques of reverse transcription polymerase chain reaction (RT-PCR) and in situ hybridization to investigate the expression of VEGF mRNA in first trimester decidua and trophoblast, and term amnion, chorion and placenta, to determine whether VEGF plays a role in angiogenesis during growth and development of the placenta. 


\section{Materials and Methods}

\section{Tissue collection and cell culture}

Tissue was collected from patients following informed consent, and the study was passed by the Ethical Committee of the Cambridge District Health Authority. First trimester tissue samples were collected from patients following termination of pregnancy, and term placenta and membranes from women undergoing elective Caesarian section for breech presentation. Tissue was washed in sterile PBS and snap frozen in liquid nitrogen.

The choriocarcinoma cell line BeWo (American Tissue Type Collection, Rockville MD) was grown in Hams F12 according to the ATCC recommendations. Cells were grown to $80 \%$ confluence, harvested by trypsin-EDTA (ICN Flow, Irvine) treatment, washed in ice cold PBS and the cell pellet was frozen at $-70^{\circ} \mathrm{C}$.

\section{Preparation of RNA and reverse transcription polymerase chain reaction ( $R T-P C R)$}

RNA was prepared from frozen tissue by the method of Chomsninzski and Sarchi (1987). Briefly, tissue was homogenized in a buffer containing guanidinium thiocyanate (Gibco, Livingstone) and total RNA was purified by acid phenol extraction and ethanol precipitation. cDNA was synthesized using AMV reverse transcriptase (Super RT:HT Biotechnology, Cambridge, UK). Total RNA (3-5 $\mu \mathrm{g})$ was primed with oligo dT (Pharmacia, Milton Keynes, Bucks), according to the manufacturers instructions for $60 \mathrm{~min}$ at $42^{\circ} \mathrm{C}$. Amplification was carried out by nested PCR using two pairs of primers. A portion of the reverse transcriptase products was initially amplified using primers I and J (see below) with Amplitaq (Cetus, Emeryville, CA), in the manufacturer's recommended buffer. The reaction mixture $(50 \mu \mathrm{l})$ was amplified for 30 cycles as follows: $94^{\circ} \mathrm{C}$ $60 \mathrm{~s}, 54^{\circ} \mathrm{C} 50 \mathrm{~s}, 72^{\circ} \mathrm{C} 30 \mathrm{~s}$. One microlitre of the product was transferred to a fresh $50 \mu \mathrm{l}$ reaction mix containing primers $\mathrm{G}$ and $\mathrm{H}$, and reamplified for 20 cycles using similar conditions, except that the primer annealing step was at $60^{\circ} \mathrm{C}$. Ten microlitres of the products was then analysed by $2 \%$ agarose gel electrophoresis. The identity of the PCR products was confirmed by cloning each band and sequencing it as described by Charnock-Jones et al. (1993). The primers used in this study are shown below. Numbering of bases is according to Tischer et al. (1991).

\begin{tabular}{lll}
\multicolumn{2}{l}{ Bases } & $5^{\prime}$ \\
$\mathrm{I}$ & $(-94$ to -77$)$ & TCGGGCCTCCGAAACCAT \\
$\mathrm{J}$ & $(\mathbf{7 2 6}$ to 743, antisense $)$ & GCGCAGAGTCTCCTCTTC \\
$\mathrm{G}$ & $(-75$ to -56$)$ & ATGAACTTTCTGCTGTCTTGGGT \\
$\mathrm{H}$ & $(551$ to 570, antisense $)$ & TCACCGCCTCGGCTTGTCAC
\end{tabular}

These primers span exon-intron boundaries; amplification of contaminating genomic DNA would therefore be readily detected.

\section{In situ hybridization}

In situ hybridization was carried out according to the method of Sharkey et al. (1992). Cryostat sections were collected onto slides coated with poly-L-lysine (Sigma, Poole), air dried and fixed in $4 \%$ paraformaldehyde in PBS for $20 \mathrm{~min}$ at $4^{\circ} \mathrm{C}$. Slides were dehydrated through a series of alcohols and stored at $-70^{\circ} \mathrm{C}$. The sections were probed with a ${ }^{35} \mathrm{~S}$-labelled antisense RNA probe transcribed from a clone containing $V \mathrm{EGF}_{165}$. This probe recognizes all VEGF isoforms. A probe transcribed from the sense strand was used as a control for nonspecific hybridization. Approximately $2 \times 10^{6}$ c.p.m. of ${ }^{35}$ S-UTP were incorporated per microgram of plasmid template. After acetylation, the air dried slides were prehybridized in $50 \%$ formamide, I $\times$ Denhardt's, $20 \mathrm{mmol}^{\text {Tris}}-\mathrm{HCl}^{-1} \mathrm{pH} 8,0.3 \mathrm{~mol} \mathrm{NaCl}^{-1}$, $5 \mathrm{mmol}$ EDTA $\mathrm{I}^{-1}, 10 \mathrm{mmol}$ sodium phosphate $\mathrm{I}^{-1}$ and $0.5 \mathrm{mg}$ yeast tRNA ml, at $50^{\circ} \mathrm{C}$ for $1 \mathrm{~h}$. The prehybridization buffer was removed and hybridization buffer added, containing in addition to the above $10 \%$ dextran sulfate (Pharmacia), $50 \mathrm{mmol}$ dithiothreitol $\mathrm{I}^{-1}$ and $1 \times 10^{5}$ d.p.m. ${ }^{35} \mathrm{~S}$-labelled sense or antisense RNA probe $\mu \mathrm{l}^{-1}$. Hybridization was carried out at $50^{\circ} \mathrm{C}$ for $16 \mathrm{~h}$. The slides were washed twice in $2 \times \operatorname{SSC}(1 \times$ SCC is $0.15 \mathrm{~mol} \mathrm{NaCl} \mathrm{l}^{-1} 0.015 \mathrm{~mol}$ sodium citrate $\mathrm{l}^{-1}$ ) and $14 \mathrm{mmol}$ 2-mercaptoethanol $\mathrm{l}^{-1}$ at $50^{\circ} \mathrm{C}$ for $20 \mathrm{~min}$, rinsed in $2 \times \mathrm{SSC}$ and treated with RNAse A (10 $\mathrm{g} \mathrm{ml}^{-1}$, from Sigma) for $30 \mathrm{~min}$ at $37^{\circ} \mathrm{C}$ in $0.5 \mathrm{~mol} \mathrm{NaCl} 1^{-1}, 10 \mathrm{mmol}$ Tris $1^{-1} \mathrm{pH} \mathrm{7.0,1} \mathrm{mmol}$ EDTA $1^{-1}$. The slides were washed twice in $2 \times \mathrm{SSC}$ at room temperature for $15 \mathrm{~min}$ followed by $0.1 \times \mathrm{SSC}$ for $60 \mathrm{~min}$ at $65^{\circ} \mathrm{C}$ and dehydrated in an ethanol series. Autoradiography was carried out at $4^{\circ} \mathrm{C}$ for $2-3$ weeks by coating the slides in Ilford $\mathrm{K} 5$ emulsion (Ilford Ltd, Cheshire). The slides were developed with Kodak developer D19 (Kodak, Rochester, New York) fixed and counterstained with haemalum.

\section{Immunohistochemistry}

Cryostat sections were fixed with ice-cold acetone for $10 \mathrm{~min}$ and rinsed in PBS. Endogenous peroxidase activity was destroyed by incubation in PBS with 3\% hydrogen peroxide. Blocking was carried out with $10 \%$ rabbit serum in PBS followed by incubation with primary antibody for $1 \mathrm{~h}$ at room temperature. Anti-cytokeratin antibody and macrophage CD68 antibody were from Dako (Copenhagen); Leu-M3 was from Beckton Dickinson (San Jose). These were detected with biotinylated rabbit anti-mouse followed by $A B C$ peroxidase (Vector Labs, Peterborough). Sections were counterstained with haemalum and mounted in Depex (BDH, Poole).

\section{Results}

\section{RT-PCR of VEGF}

Total RNA from first trimester tissue and term placenta was reverse transcribed and subjected to two rounds of amplification by PCR using the primer pairs I, J followed by G, H. Four products identical in size to those described in endometrium of nonpregnant patients were identified in all tissues examined (Fig. 1). These were sequenced to confirm their identity, and corresponded to mRNA species that predict VEGF isoforms of $189,165,145$ and 121 amino acids, respectively. A control reaction without input cDNA gave no product, eliminating the possibility of contamination (lane $\mathrm{C}$ ). The ratios of the various isoforms appear to vary slightly between some of the tissues Downloaded from Bioscientifica.com at 04/26/2023 11:58:40AM 
$\begin{array}{llllllllllll}1 & 2 & 3 & 4 & 5 & 6 & 7 & 8 & 9 & \mathrm{C} & M\end{array}$

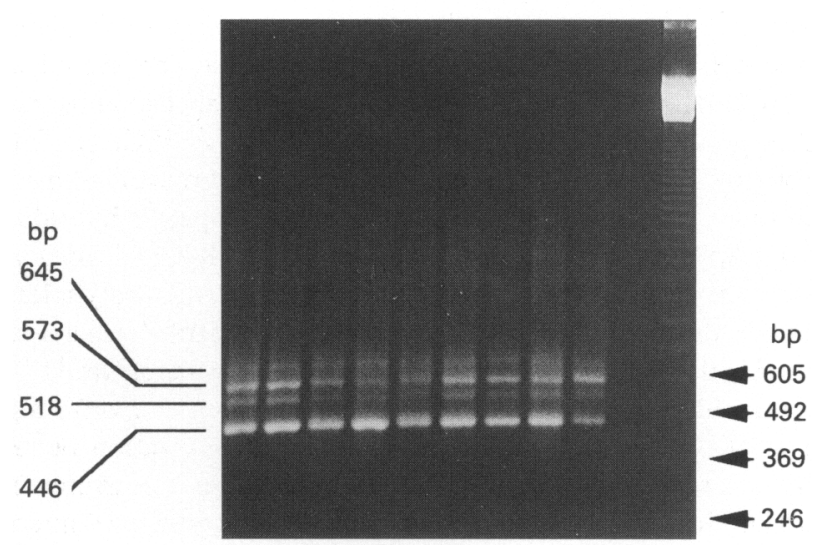

Fig. 1. Agarose gel showing the products of nested reverse transcription polymerase chain reaction (RT-PCR) amplification of cDNA using primers $I$ and $J$ followed by primers $G$ and $H$. cDNA was from the following tissue: proliferative endometrium (lane 1), secretory endometrium (lane 2), term placenta (3), amnion (4), chorion (5), first trimester trophoblast (6), first trimester decidua (7 and 8; 8 weeks and 10 weeks, respectively), BeWo choriocarcinoma cell (9), control reaction with no input cDNA (lane C). Markers (M) are 123 base pair (bp) ladder. Sizes of the four vascular endothelial growth factor (VEGF) isoforms are shown in base pairs.

shown; however, this pattern was not always consistent on repeating the experiment with different samples, and probably represents minor variations between samples from different patients. The choriocarcinoma cell line BeWo was also found to express the same four variants of VEGF mRNA. cDNA encoding the 206 amino acid isoform was not seen in any of the tissues examined.

\section{In situ hybridization}

First trimester. To identify the site of expression of VEGF mRNA, we carried out in situ hybridization on samples of first trimester decidua, trophoblast and term placenta. In first trimester trophoblast, weak VEGF mRNA expression was demonstrated in both cytotrophoblast and syncytiotrophoblast surrounding the villi (Fig. 2c, d). Isolated cells within the villi also expressed VEGF. These are probably Hofbauer cells, a type of fetal macrophage within the villous mesenchyme, which stain positively with the macrophage $\mathrm{CD} 68$ antibody (labelled $\mathrm{H}$, in Fig. $2 \mathrm{~d}$, f). In most villi, a moderate expression was seen; however, in some isolated villi all these mesenchymal cells were expressing VEGF very strongly (data not shown). This suggests that VEGF expression within each villus may be regulated by local factors.

Hybridization was seen at several sites within the decidua. Strong expression of VEGF mRNA was seen in glandular epithelium (labelled G in Fig. 2d). Expression was also seen in scattered cells within the decidual stroma. The strongest site of VEGF expression was cells in the decidua at the uteroplacental junction, immediately adjacent to Nitabuchs stria of fibrinoid (Fig. 2c, d). These cells could be extravillous trophoblast (EVT), macrophages, stromal cells or large granular lymphocytes (LGL), all of which occur in this region. Serial sections were stained with cytokeratin to identify EVT, and Leu-M3 (antiCD14) to identify decidual macrophages (Fig. 2e, h). Hofbauer cells in the villi at first trimester stain very weakly with Leu-M3; these were therefore stained with CD68. This antibody was found to stain both macrophages and stromal cells in the decidua (Fig. 2f). The serial sections suggested that the distribution of strongly expressing cells did not match that of EVT identified by the cytokeratin antibody (Fig. 2c, e). Sections of decidua, taken away from the implantation site, which contained macrophages but no EVT showed a similar pattern of expression by scattered cells, although the level of expression was lower than at the implantation site (data not shown). Furthermore, the distribution of these VEGF-expressing cells in the decidua did not resemble that of large granular lymphocytes, which have a characteristic distribution around glands (Fig. 2d, and Bulmer and Sunderland, 1984). We believe that these cells are macrophages.

Term placenta. In term placenta from elective Caesarian sections, VEGF mRNA expression was demonstrated in syncytiotrophoblast cells surrounding the villi. In addition, large cells in the maternal decidual bed showed strong expression (labelled E in Fig. 3c, d). Immunohistochemical localization of cytokeratin in these cells in serial sections suggested that they are extravillous trophoblast, which have invaded the maternal bed (labelled E in Fig. 3c, e). Hofbauer cells, scattered within the villous mesenchyme, were also seen to express VEGF mRNA, as in first trimester villi (labelled H in Fig. 3c, d).

Amnion and chorion were also analysed by in situ hybridization, since these were shown to express VEGF mRNA by RTPCR (Fig. 1). The amnion is a single layer of epithelial cells and is nonvascular; however, VEGF was clearly expressed in this tissue (labelled A in Fig. 4c, d). The pattern of expression in the chorion was more complex with weak expression in the layer of extravillous trophoblast (labelled T), and much stronger expression in scattered cells in the fibrous layer of connective tissue (Fig. 4c, d). Immunohistochemical staining of serial sections with antibodies suggest that these cells are tissue macrophages as their distribution closely matches that of cells staining positively for CD14 (Fig. 4e). In addition, there are few large granular lymphocytes at this site in term placenta (Bulmer and Sunderland, 1984). There was no significant expression by fetal macrophages (labelled F, Fig. 4e).

\section{Discussion}

The study reported here demonstrates the presence of mRNA encoding VEGF in human decidua and trophoblast in first trimester and term placenta. The same four isoforms that occur in endometrium of nonpregnant patients were identified by RTPCR. The recently described VEGF 206 isoform was not detected; this isoform has been detected only in a fetal liver cDNA library (Houck et al, 1992). Peripheral leucocytes express only two isoforms, VEGF ${ }_{165}$ and VEGF ${ }_{121}$ (Charnock-Jones et al., 1993); expression of the other isoforms is therefore clearly from placental tissues. It is not clear from these data whether any cell type expresses all these isoforms simultaneously. For example human vascular smooth muscle cells express only three isoforms (Tischer et al., 1991). However, in the study reported Downloaded from Bioscientifica.com at 04/26/2023 11:58:40AM 

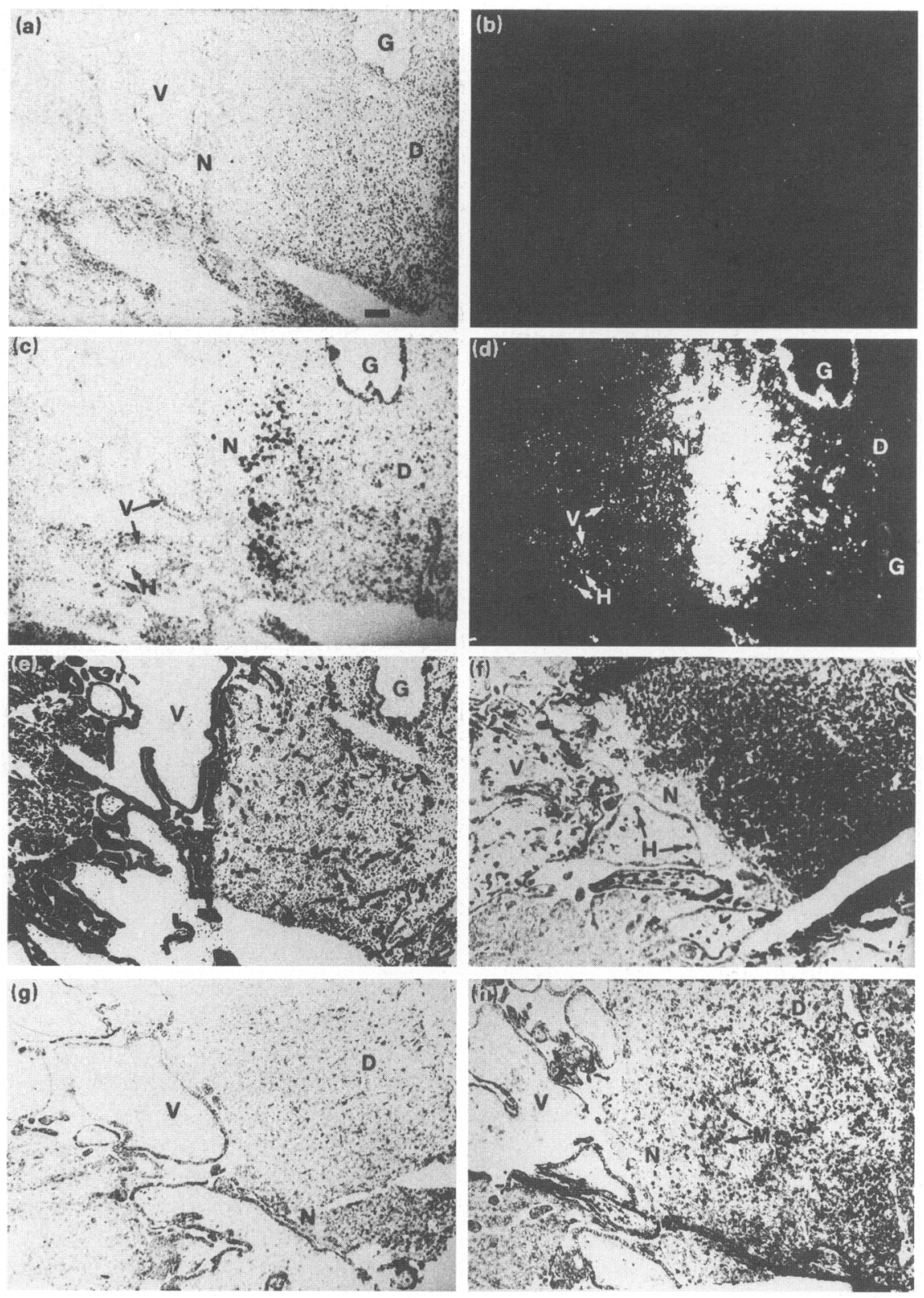

Fig. 2. In situ hybridization analysis of vascular endothelial growth factor (VEGF) mRNA expression at implantation site, ( 9 weeks gestation). Hybridization signal is shown as bright grains in darkfield photomicrographs. Panel (a) was probed with sense control probe, (c) probed with antisense VEGF probe. Panels (b) and (d) are darkfield photomicrographs of (a) and (c), respectively. Villous trophoblast $(\mathrm{V})$ is shown adjacent to maternal decidua (D), separated by Nitabuch's layer $(N)$. Hofbauer cells within fetal villi and which express VEGF are labelled $H$. Glands within maternal decidua are labelled G. Panels (e), ( $f$ ) and (h) are serial sections stained immunohistochemically with anti-cytokeratin, anti-CD68 and anti-CD14 antibodies to detect trophoblast and macrophages, respectively. Anti-CD68 stains Hofbauer cells in the villi, but both macrophages and stromal cells in the decidua; Leu-M3 (anti-CD14) was therefore used to detect macrophages ( $M$ in panel $(h)$ ) in the decidua. Panel $(\mathrm{g})$ is a control section treated with no primary antibody. All sections were counterstained with haemalum. Scale bar in (a) represents $100 \mu \mathrm{m}$.

here, the choriocarcinoma cell line BeWo was shown to express all four isoforms.

The four different isoforms of VEGF seen in reproductive tissue arise from alternative splicing of exons $6-8$ in the VEGF mRNA. VEGF 189 contains exons $1-8$; $V \mathrm{VGF}_{165}$ lacks exon 6;
VEGF $_{145}$ lacks exon 7; and VEGF ${ }_{121}$ lacks exons 6 and 7. These isoforms have significantly different properties. $\mathrm{VEGF}_{165}$ and VEGF $_{121}$ are secreted by transfected mammalian cells, and conditioned medium promotes endothelial cell growth. However, VEGF $_{189}$ and VEGF $_{206}$ are poorly secreted, and conditioned Downloaded from Bioscientifica.com at 04/26/2023 11:58:40AM 

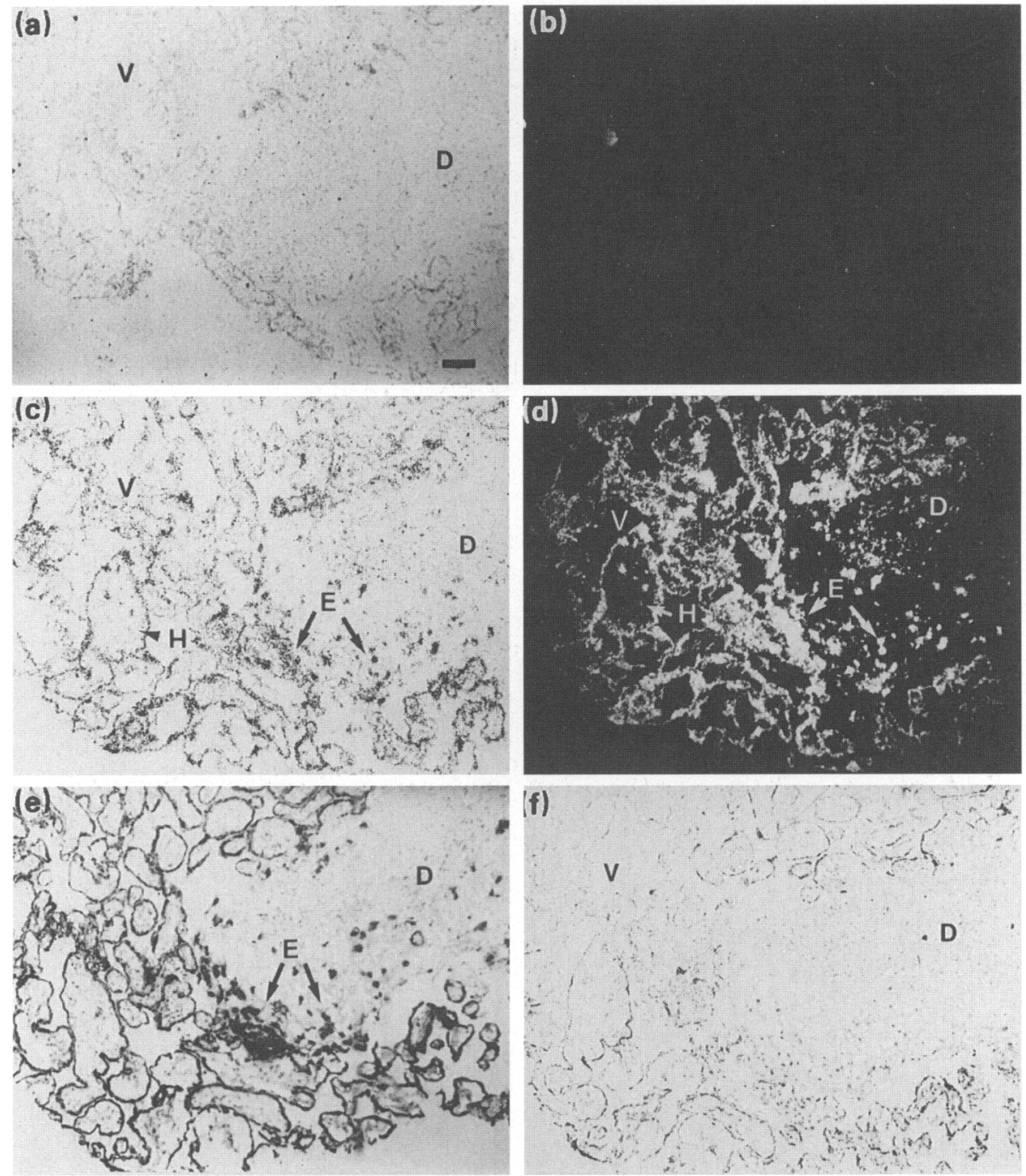

Fig. 3. In situ hybridization analysis of vascular endothelial growth factor (VEGF) mRNA expression in serial sections of term placenta. Panel (a) was probed with sense control probe, and (c) was probed with antisense VEGF probe. Panels (b) and (d) are darkfield photomicrographs of (a) and (c), respectively. Panel (e) is stained immunohistochemically with anticytokeratin antibody to detect trophoblast, and panel $(f)$ is a negative control. Scattered cells within the villi that show VEGF expression are probably Hofbauer cells $(\mathrm{H})$. Extravillous trophoblast $(\mathrm{E})$ in the decidua are strongly positive. All sections were counterstained with haemalum. V: villous trophoblast; D: maternal decidua. Scale bar in (a) represents $100 \mu \mathrm{m}$.

medium from transfected cells has little or no mitogenic activity on endothelial cells (Houck et al., 1992). All four species induce extravasation in a Miles-type assay, although the two larger isoforms appear much more potent. VEGF ${ }_{145}$ has not yet been shown to have biological activity. This form contains exon 6 , which is believed to contain the nuclear targeting signal responsible for the apparent intracellular sequestration of $\mathrm{VEGF}_{189}$ and VEGF $_{206}$ (Houck et al., 1992). It is therefore possible that $\mathrm{VEGF}_{145}$ may also be largely intracellular.

In situ hybridization has revealed several sites of synthesis of VEGF mRNA in tissue obtained from first trimester pregnancy. The cell types found to express VEGF mRNA in this study include maternal glandular epithelium, and both fetal and maternal macrophages. Synthesis was also seen in the villous trophoblast around fetal villi, but was not detected in EVT migrating through the maternal decidua in the first trimester. However, at term, EVT did express VEGF. Expression of VEGF mRNA has been reported in a wide variety of both embryonic and adult tissues (Ferrara et al., 1991). In addition to tissues in which angiogenesis is apparent, such as embryonic tissue, and the corpus luteum in the adult ovary (Phillips et al., 1990), expression has been shown in tissues undergoing no obvious angiogenesis. These tissues include epithelial cells of lung alveoli, renal glomeruli, adrenal cortex and cardiac myocytes, and this finding has led to the suggestion that in these tissues VEGF might play a role in regulating microvascular permeability (Berse et al., 1992; Ferrara, 1992). It is possible that the VEGF synthesized by EVT scattered in the maternal decidua in term placenta, when large scale angiogenesis has ceased, plays a similar role. 

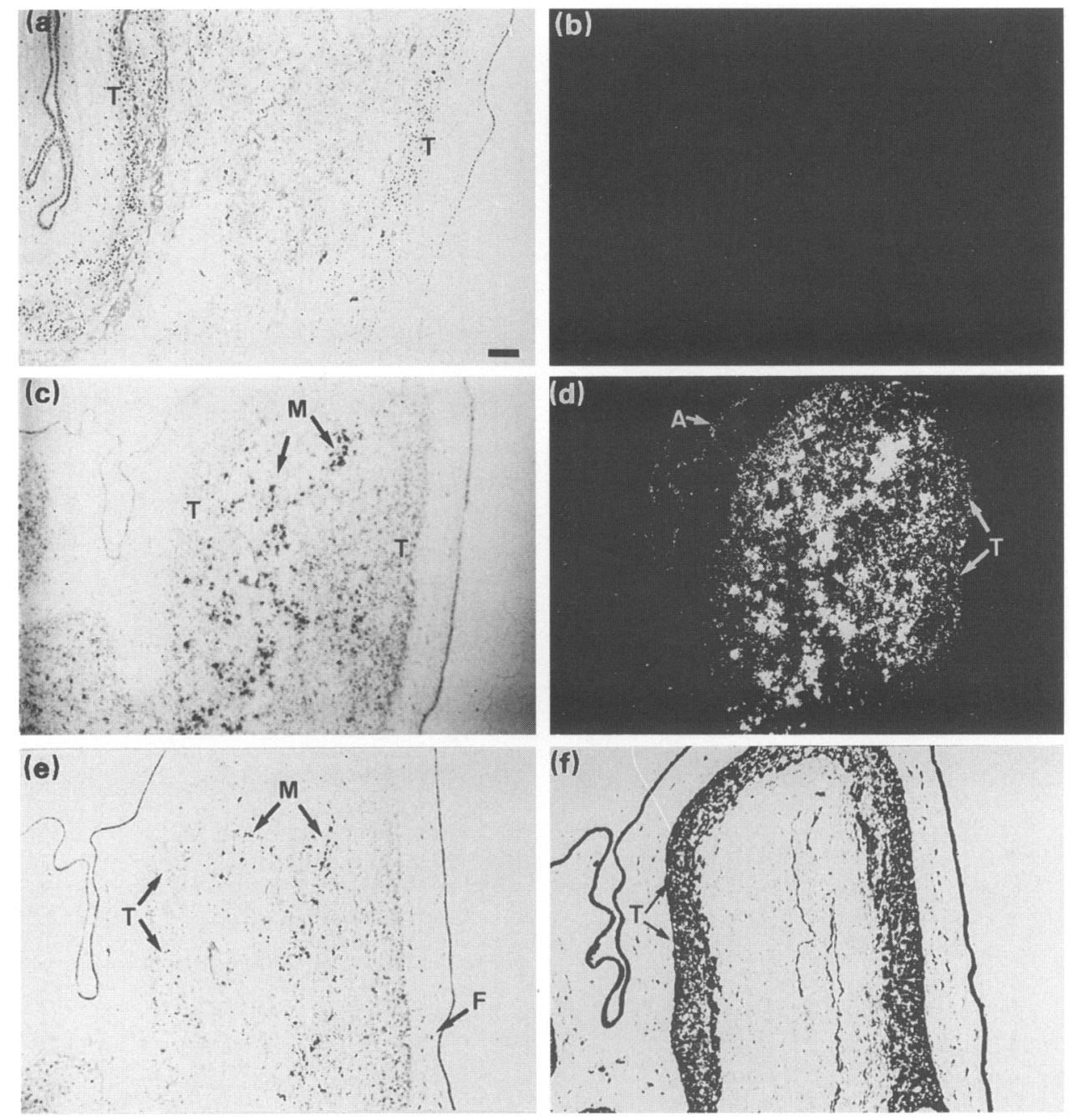

Fig. 4. In situ hybridization analysis of vascular endothelial growth factor (VEGF) mRNA expression in term amnion and chorion. Panel (a) was probed with sense control probe and (c) was probed with antisense VEGF probe. Panels (b) and (d) are darkfield photomicrographs of (a) and (c), respectively. Amnion (A) and trophoblast (T) are weakly positive in panel (d). Panels (e) and (f) are serial sections stained immunohistochemically with anti-CD14 and anti-cytokeratin antibodies to detect macrophages, and trophoblast, respectively. Maternal macrophages $(\mathrm{M}$ in panel (e) are strongly positive; however, fetal macrophages gave no signal. All sections were counterstained with haemalum. Scale bar in (a) represents $100 \mu \mathrm{m}$.

On the fetal side of the placenta, the predominant site of expression is isolated cells within the placental villi, which are almost certainly Hofbauer cells, which are fetally derived macrophages. These are adjacent to fetal capillaries, and VEGF from these cells may be involved in the extensive angiogenesis of fetal blood vessels during placental growth. At term, these cells are still expressing VEGF, and at this stage a role in the maintenance of the endothelium or regulation of vascular permeability seems likely.

In the maternal decidua many cells express VEGF mRNA, both at the site of implantation and at lower levels elsewhere in the decidua. The pattern of distribution of these cells observed in the study reported here when compared with serial sections stained to visualize EVT and macrophages suggests that they are macrophages. Formal demonstration of this will be possible when an antibody to VEGF which is suitable for immunocytochemistry becomes available. The increased expression by cells at the implantation site adjacent to Nitabuch's layer suggests that either recruitment of a subset of highly expressing cells to the site, or upregulation of VEGF expression by local factors occurs. Nitabuchs layer is a zone of necrosis where the trophoblastic shell contacts maternal decidua. A similar phenomenon has recently been reported at the necrotic margins of human gliomas, where VEGF has been implicated in the angiogenesis induced by these tumours in vivo (Shweiki et al., 1992). These authors hypothesized that VEGF expression is induced in glioma cells by hypoxia, and results in a localized angiogenic response. It is possible that localized hypoxia is responsible for the high VEGF expression in macrophages adjacent to Nitabuch's layer; however, other local factors, such as cytokines from fetal villi, could also be responsible.

A possible role for the high levels of VEGF expression seen at the site of implantation is suggested by recent measurements of capillary diameter at the implantation site in rats (Tawia and Rogers, 1992). These authors showed that large increases in 
capillary diameter occur in response to local signals associated with the implanting embryo, and suggest that these are associated with alterations in the endothelial cells or the basement membrane. It will be interesting to determine whether macrophages at the site of implantation in rats show high VEGF expression. If so, VEGF, acting on the endothelial cells, could be the factor mediating these effects on capillaries.

In osteopetrotic mice, which totally lack the cytokine colonystimulating factor-1 (CSF1), op/op females have fewer macrophages in the uterus (Pollard et al., 1991). These mice show more fetal resorption and greatly decreased fertility. If macrophages play an important role in angiogenesis during placental development, the failure of op/op mice to recruit macrophages to the implantation site may explain the increased fetal resorption seen in these mice.

The expression of VEGF by the glandular epithelium appears to be under the control of steroid hormones. Oestradiol increased VEGF expression in the adenocarcinoma cell line Hec 1A in vitro (Charnock-Jones et al., 1993). We have shown that in endometrium of nonpregnant patients, VEGF expression by the glands is greatly increased in the luteal phase of the cycle. This finding suggests that progesterone does not antagonize VEGF expression stimulated by oestradiol, but enhances preferential expression in the glands, which is maintained into the first trimester of pregnancy. It, therefore, seems likely that the high expression of VEGF by glandular epithelium in the uterus of pregnant females is mediated by steroids. Glandular expression of VEGF is not localized to the implantation site. The whole uterus undergoes considerable hypertrophy during pregnancy, and VEGF produced by the glands may play a role in the growth of the uterine vasculature which accompanies this.

This study has revealed a complex pattern of VEGF expression, by glandular epithelium, villous and extravillous trophoblast, and suggests an important role in angiogenesis for fetal and maternal macrophages, by virtue of their location and high expression of VEGF. Expression of VEGF appears to be controlled by several factors including steroids, and local factors which may include hypoxia and cytokines. In some patients with intrauterine growth retardation, impaired placental blood flow is associated with a reduction in numbers of blood vessels in secondary and tertiary stem villi (Bracero et al., 1989; Kuhlmann et al., 1990). It is possible that alterations in the pattern of VEGF expression in early pregnancy play a role in these effects. It will be necessary to determine whether the isoforms of VEGF are differentially expressed at the sites that we have identified and whether this pattern is altered in placentae of patients with intrauterine growth retardation.

The authors would like to thank the Consultant, Theatre and Pathology staff of Addenbrookes' Hospital, Cambridge for their help with this study. Thanks also to A. Davenport of the Department of Clinical Pharmacology for advice and assistance with autoradiography, and to S. Brown for expert histology. A. Sharkey was supported by MRC project grant G8909970SB, D. S. Charnock-Jones was supported by MRC project grant G8928836SB. C. Boocock was supported by Birthright grant S1/91.

\section{References}

Berse B, Brown LF, Van De Water L, Dworak HF and Senger DR (1992) Vascular permeability factor (VEGF) gene is expressed differentially in normal tissues, macrophages and tumours Molecular Biology of the Cell 3 211-220
Bracero LA, Beneck D, Kirshenbaum N, Peiffer M, Stalter P and Schulman H (1989) Doppler velocimetry and placental disease American Joumal of Obstetrics and Gynecology $161388-393$

Bulmer JN and Sunderland CA (1984) Immunohistological characterisation of lymphoid cell populations in the early human placental bed Immunology 52 349-357

Charnock-Jones DSC, Sharkey AM, Rajput-Williams J, Burch D, Schofield PJ, Fountain SA, Boocock CA and Smith SK (1993) Identification and localization of alternately spliced mRNAs for vascular endothelial growth factor in human uterus and steroid regulation in endometrial carcinoma cell lines Biology of Reproduction 48 1120-1128

Chomsninzski P and Sarchi E (1987) Single step method of RNA isolation by guanidine thiocyanate-phenol-chloroform extraction Analytical Biochemistry $162156-159$

De Vries C, Escobedo JA, Ueno H, Houck K, Ferrara N and Williams LT (1992) The fms-like tyrosine kinase, a receptor for vascular endothelial growth factor Science 255 989-991

Ferrara N and Henzel WJ (1989) Pituitary follicular cells secrete a novel heparinbinding growth factor specific for vascular endothelial cells Biochemical and Biophysical Research Communications 161 851-858

Ferrara N, Leung DW and Phillips HS (1991) Molecular characterisation and distribution of vascular endothelial growth factor. In Neuroendocrine Perspectives Vol 9 pp 123-157 Eds EE Muller and RB MacLeod. SpringerVerlag, New York

Ferrara N, Houck K, Jakeman L and Leung DW (1992) Molecular and biological properties of the vascular endothelial growth factor family of proteins Endocrine Reviews 13 18-32

Ferriani RA, Charnock-Jones DSC, Prentice A, Thomas EJ, Brown KB and Smith SK (1993) Immunohistochemical localisation of acidic and basic fibroblast growth factors in normal human endometrium and endometriosis and the identification of the mRNA by PCR Human Reproduction 8 11-16

Findlay JK (1986) Angiogenesis in reproductive tissue Journal of Endocrinology $111357-366$

Folkman J (1985) Tumor angiogenesis Advances in Cancer Research 43 175-203

Folkman J and Klagsbrun M (1987) A family of angiogenic peptides Nature 329 $671-672$

Gospodarowicz D, Ferrara N, Schweigerer L and Neufeld G (1987) Structural characterization and biological functions of fibroblast growth factor Endocrine Reviews 8 95-114

Gospodarowicz D, Abraham JA and Schilling J (1989) Isolation and characterisation of a vascular endothelial cell mitogen produced by pituitary-derived folliculostellate cells Proceedings of National Academy of Sciences USA 86 7311-7315

Houck KA, Ferrara N, Winer J, Cachianes G, Bing L and Leung DW (1991) The vascular endothelial growth factor family: identification of a fourth molecular species and characterization of alternative splicing of RNA Molecular Endocrinology 5 1806-1814

Jakeman LB, Altar CA, Winer J, Bennet GL and Ferrara N (1992) Binding sites for vascular endothelial growth factor are localised on endothelial cells in adult rat tissues Joumal of Clinical Investigation 89 244-253

Klagsbrun M and D'Amore PA (1991) Regulators of angiogenesis Annual Reviews of Physiology 53 217-239

Kuhlmann RS, Werner AL, Abramowicz J, Warsof SL, Arrington J and Levy DL (1990) Placental histology in fetuses between 18 and 23 weeks gestation with abnormal karyotype American Journal of Obstetrics and Gynecology 163 $1264-1270$

Phillips HS, Haines J, Leung DW and Ferrara N (1990) Vascular endothelial growth factor is expressed in rat corpus luteum Endocrinology 127 965-967

Pollard JW, Hunt JS, Wiktor-Jedrzejczak W and Stanley ER (1991) A pregnancy defect in the osteopetrotic (op/op) mouse demonstrates the requirement for CSF-1 in female fertility Developmental Biology 148 273-283

Sharkey AM, Charnock-Jones DS, Brown KD and Smith SK (1992) Expression of mRNA for Kit-ligand in human placenta: localisation by in situ hybridisation and identification of alternatively spliced variants Molecular Endocrinology 6 1235-1241

Shweiki D, Hin A, Soffer D and Keshet E (1992) VEGF induced by hypoxia may mediate hypoxia-initiated angiogenesis Nature 359 843-845

Tawia SA and Rogers PAW (1992) In vivo microscopy of subepithelial capillary plexus of the endometrium of rats during embryo implantation Journal of Reproduction and Fertility $96673-680$

Tischer E, Mitchell R, Hartman T, Silva M, Gospodarovicz D, Fiddes JC and Abraham JA (1991) The human gene for vascular endothelial growth factor Journal of Biological Chemistry 26611 947-11 954 